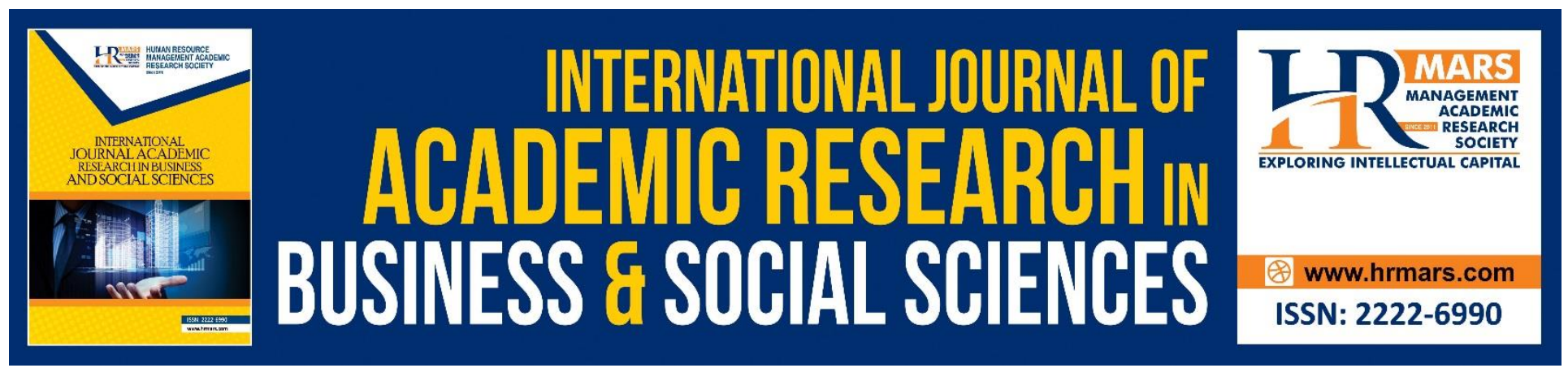

\title{
The Relationship between Supervision Contextual Factors and Supervision Outcomes
}

\author{
Nor Mazlina Ghazali, Wan Marzuki Wan Jaafar, Rohani Ahmad Tarmizi, \\ Sidek Mohd Noah
}

To Link this Article: http://dx.doi.org/10.6007/IJARBSS/v8-i12/5153

DOI: $10.6007 /$ IJARBSS/v8-i12/5153

Received: 21 Nov 2018, Revised: 29 Dec 2018, Accepted: 30 Dec 2018

Published Online: 31 Dec 2018

In-Text Citation: (Ghazali, Jaafar, Tarmizi, \& Noah, 2018)

To Cite this Article: Ghazali, N. M., Jaafar, W. M. W., Tarmizi, R. A., \& Noah, S. M. (2018). The Relationship between Supervision Contextual Factors and Supervision Outcomes. International Journal of Academic Research in Business and Social Sciences, 8(12), 1059-1072.

\section{Copyright: (c) 2018 The Author(s)}

Published by Human Resource Management Academic Research Society (www.hrmars.com)

This article is published under the Creative Commons Attribution (CC BY 4.0) license. Anyone may reproduce, distribute, translate and create derivative works of this article (for both commercial and non-commercial purposes), subject to full attribution to the original publication and authors. The full terms of this license may be seen

at: http://creativecommons.org/licences/by/4.0/legalcode

\section{Vol. 8, No. 12, 2018, Pg. 1059 - 1072}

Full Terms \& Conditions of access and use can be found at http://hrmars.com/index.php/pages/detail/publication-ethics 


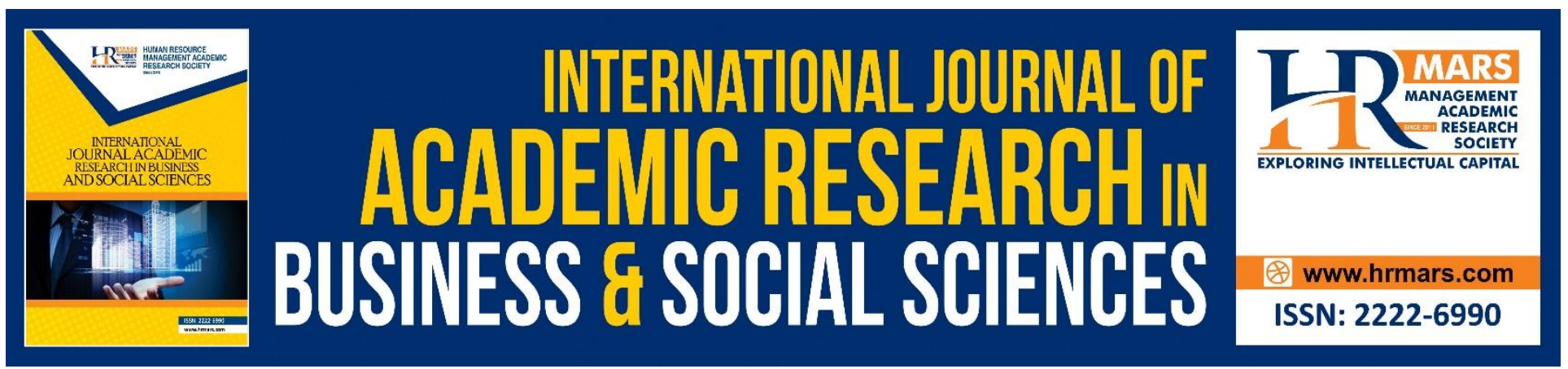

\title{
The Relationship between Supervision Contextual Factors and Supervision Outcomes
}

\author{
Nor Mazlina Ghazali, Wan Marzuki Wan Jaafar, Rohani Ahmad \\ Tarmizi, Sidek Mohd Noah
}

Faculty of Educational Studies, University Putra Malaysia, 43400 UPM Serdang, Selangor Darul

Ehsan, Malaysia

\begin{abstract}
The purpose of this study was to investigate the influence of the supervisory relationship and contextual supervision factors on supervision outcomes among trainee counsellors. There were 120 trainee counsellor respondents and 18 supervisors from four universities UM, UUM, UMT and UMS. The respondents were selected using the stratified random sampling technique. This study utilized the correlational research design. His research revealed there was no significant correlations between supervision contextual factors (supervisees' and supervisors' counselling orientation and supervisees' cultural knowledge and awareness) and supervision outcomes. There were several recommendations outlined by the study which included, (i) the supervision contextual factors (cultural knowledge and awareness) should be examined from the supervisors' perspective, (ii) future researchers should personally give explanations to the respondents when conducting the question and answer sessions and (iii) future researchers could also expand this investigation by examining the differences between supervision interaction of the supervisors and the supervisees.
\end{abstract}

Keywords: Supervisors' and supervisees' counselling; orientation and supervisees' cultural knowledge and awareness; supervision outcomes

\section{Introduction}

There were few literatures on counselling supervision in Malaysia that investigated factors contributing to supervision outcomes. Wan Marzuki Wan Jaafar (2011) reported there should be a strong emphasis on counsellors' performance in order to produce competent counsellors. Counsellors' performance is one of the essential components in the supervision outcomes besides satisfaction. Supervision outcomes are reflected by the supervisory process. The supervisory process involves several components such as supervisory relationships and supervision contextual factors. The System Approach of Supervision Model (1995) outlined that the supervisory relationship and supervision contextual factors are salient in identifying the supervision outcomes. Supervisors and trainee counsellors learned and developed through the supervisory process. 
The findings from Wan Marzuki Wan Jaafar (2007) stated serious attention should be given on the supervision of counsellors where he found the low rate of performance affected the development of the trainee counsellors. Due to this situation, research related to factors influencing supervision outcomes (satisfaction and performance) amongst trainee counsellors should be conducted. However, current research focused more on investigating the influence of working alliance on therapy outcomes. To determine factors influencing the supervision outcomes, the contextual factors should be taken into account. Contextual factors are one of the critical components under the System Approach of Supervision Model (SAS) (1995). Theoretical orientation is a form of contextual factor in supervision. There is a lack of research in examining the relationship between theoretical orientation and supervision outcome (Storm, 2002). Previous researches were mostly conducted on the early stages of training and not during the practicum or internship (Worthington, 1987). Hence this study took into account the theoretical orientation and its influence on supervision outcomes. Other factors included as variables in the study were cultural knowledge and awareness. According to Storm (2002), research in cultural knowledge and awareness rarely emerged unless explicitly studied. Research in this area was mainly theoretical based rather than the empirical in nature (Chang, Hays \& Shoffner, 2003).

\section{Objective}

To investigate the relationship between supervision contextual factors (supervisors' and supervisees' counselling orientation and supervisees' cultural knowledge and awareness) and supervision outcomes.

\section{Hypothesis of the Study}

Ho1: There is no significant relationship between supervisors' and supervisees' counselling orientation and supervision outcomes.

Ho2: There is no significant relationship between supervisees' cultural knowledge and awareness and supervision outcomes.

\section{Literature Review}

Supervisors and Supervisees' Counselling Orientations and Supervision Outcomes. The previous research explained theoretical orientations failed to prove the relationship with the therapy outcomes (Poznanski \& McLennan, 2003). Another findings showed there was no correlation between theoretical orientation and outcomes. Hence the diminished interest in this area of research. Discussion on supervision contextual factors (supervisors and supervisees' counselling orientations) entitled 'The Effects of supervisors and supervisees' theoretical orientations and supervisor-supervisee matching on interns' perceptions of supervision by Putney, Martha, Worthington, Everett, McCullough and Michael ( *1992) describe the effect of matching theoretical orientation between supervisor and supervisee towards supervisees' perception. In this study, they examined theoretical orientations of supervisors, trainee counsellors, and their match (or mismatch) as predictors that might influence the perceptions of supervisors as models, roles, and foci. The research investigated the extent to which theoretical beliefs of supervisors and trainee counsellors 
(and their interaction) affect their perceptions of their supervisors. The sample of this research were 51 respondents using the Personal Data Sheet.

Findings from this particular research described that the theoretical similarity amongst trainee counsellors and supervisors was known as the trainees' perceptions on models, roles, and foci of their supervisors. Although the theoretical similarity between supervisors and trainee counsellors was not related to the perceptions of how supervisors conducted supervision, it was however strongly correlated to both perceived effectiveness of supervision and perceptions of the trainee counsellors' freedom.

From these findings, it clearly shows there was no relationship between supervisors and supervisees' counselling orientations (for example the theoretical orientation). The similarity of theories applied was not influenced by the effectiveness of the supervision process. Statistical explanations on the effectiveness of the variables described as the three predictor variables of perceived supervisor effectiveness are: greater perceived theoretical similarity, $F(1,68)=30.30, p<.0001$; greater degree of theoretical match, $F(1,68)=7.50, p<.01$; and supervisor gender (female supervisors were perceived as more effective than male supervisors), $F(1,68)=4.02, p<.05$. This three-variable model is significantly predictive of effectiveness, $F(3,72)=15.38, p<.0001$. Therefore future researchers should investigate the theoretical matching from direct behaviours and also should examine the theoretical orientations of supervisors and site supervisors, investigate the influence of theoretical similarity on the supervision process as well as supervision outcomes. Based on the suggestions given, investigations on the relation between a supervisor and supervisees' counselling orientations (for example the theoretical orientation) and supervision outcomes (satisfaction and performance) as related to the effectiveness of the supervision process should be carried out.

In addition, according to Jackson (2010) in his research entitled "Theoretical counselling orientation: an initial aspect of professional orientation and identity" implemented the experimental design which categorised samples in two groups; the control group $(N=21)$ and the experimental group ( $N$ = 21). The sample of this research were counselling students who underwent the theoretical counselling course. Participants' identity status consisted of two sub -scales; exploration and commitment. Results showed the changes in participant's identity status from T1 to T2 was 27.1 percent $(n=19)$, categorised as Force closed status, 28.6 percent $(n=20)$ was categorised as Moratorium status, and 25.7 percent $(n=18)$ as Achieved identity status. In contrast, only 18.6 percent $(n=13)$ of respondents are categorised as Diffused identity status.

The identity status was clarified by Marcia (1966), as low on Exploration and Commitment (Diffused); low on Exploration and high in Commitment (Forceclosed); high scores on Exploration and low in Commitment (Moratorium) and subsequently high scores on Exploration and high scores on Commitment were classified as Achieved status. Discussion on this research described the expected outcome from counselling theories course work was when a student was able to distinct the professional theoretical orientations in consistent with his or her personal worldviews. Students who were engaged with theoretical orientations were able to increase exploration and commitment as 
well as transform their identity status. This research did not directly mention the connection between theoretical orientation or counselling orientation with supervision outcomes. Hence, the researcher found this previous research indicated the engagement of students with theoretical abilities to change their identities. Moreover, the researcher determined the outcome from the counselling theories coursework. Based on the above findings, this study researcher developed the research hypotheses six, seven, nine and eleven.

\section{Supervisee's Cultural Knowledge and Awareness and Supervision Outcomes}

Findings from this present research did not support the previous research which indicated the relationship between trainee counsellors' perceptions on cultural sensitivity increased the level of satisfaction in supervision (Inman, 2006). Another research which discussed this variable was conducted by Walter Walter Breaux III (2005), entitled "The relationship between the cultural competence of counsellor supervisors and the satisfaction with supervision of their supervisees". Discussion on culture such as ethnicity and race was influenced by the supervisory relationship whether they acknowledged or not, person or dyad, shared the same experiences and attitudes, or either they were of the same ethnic group or race (Leong \& Wagner, as cited in Borders \& Brown, 2005). In addition, Breaux (2005) declared supervisors put more effort in acknowledging the multicultural issues than trainee counsellors. However, the discussion on cultural variables showed the positive outcomes in enhancing the supervisory relationship and supervisees' satisfaction (Gatmon et al., 2001; Duan \& Roehle, 2001 as cited in Borders \& Brown, 2005). Male cohorts showed more satisfaction level as compared to female trainee counsellors with their supervisors (JeanquartBarone 1996).

Furthermore, a discussion on multicultural issues related to conceptualizing the clients' problems was often assisted by supervisors (Ladany, Brittan-Powell, Pannu, as cited in Breaux, 2005). A trainee counsellors' attention to racial issues might have more to do with a supervisor's lack of expectations than the trainee counsellor's lack of ability. Thus, when supervisors had the expectation that trainee counsellors were considerate on the multicultural issues when conceptualizing their clients' issues, trainee counsellors might be able to demonstrate their potential (Breaux (2005). The instruments used in measuring the satisfaction of supervisees were the Supervision Satisfaction Questionnaire (SSQ) and the cultural competence was measured by the Multicultural Awareness, Knowledge, and Skills Survey: MAKSS-CE-R inventory. The respondents of this research were White male doctorallevel counselling supervisors and their master's-level supervisees in a supervisory dyad. The overall result of this research, there were no statistically significant results found with respect to the relationship between the cultural competence of the doctoral counsellor supervisors and the satisfaction with supervision of their mater's level supervisees. The central tendency of the responses on the MAKSS-CE-R suggested an average to moderate competency level in each subscale throughout the total survey. The Pearson correlation between the variables of supervisor's cultural competency and supervisees' satisfaction with supervision showed $r=.079$. This result, was able to support the eighth (8) hypothesis in this present research. The development of the research hypotheses was based on this research findings and the examination on the undergraduate counselling students in Malaysia. Findings from several researchers are reflected on hypotheses six, eight, nine and eleven. 
This research listed suggestions for future research are; the study should be extended to a larger sample of respondents and the inclusion of non registered counsellors as respondents. This may assist in enhancing the cultural competency levels and satisfaction with supervision attitudes across the counselling programs. From this suggestion, there will be opportunities to conduct the research with bigger number of samples. Emphasize should be given to the advanced stage of undergraduate counselling students who undergo the internship in organisations.

\section{Methodology}

\section{Research Design}

This study utilises the survey correlational research design involving the trainee counsellors and supervisors in public universities. Correlational research describes the statistical relation between variables.

\section{Population and Sampling Technique}

The population of this research consisted of trainee counsellors from Universiti Utara Malaysia (UUM), Universiti Malaya (UM), Universiti Malaysia Sabah (UMS) and Universiti Malaysia Terengganu (UMT). The survey sample in this study included 120 trainee counsellors from four higher institutions (UUM, UM, UMS and UMT) offering the counselling programme. The trainee counsellors from Universiti Pendididkan Sultan Idris (UPSI) were chosen for the pilot study. Universiti Putra Malaysia (UPM), Universiti Islam Sains Islam Malaysia (USIM) and Universiti Malaysia Sarawak (UNIMAS) were excluded from the study for the following reasons: (i) UPM trainee counsellors had completed their internship during the data collection; (ii) USIM did not respond and (iii) UNIMAS had no students undergoing the counselling internship for the mean time. The survey was carried out on 120 final year counselling students who were who undergoing the internship. They were selected because the trainee counsellors had achieved the level of maturity and growth in the supervision process.

This research utilised the stratified random sampling to determine the sample for the study. Stratified random sampling involves the division of population into smaller groups known as strata. In this type of sampling, the stratas are constructed based on the populations' mutual characteristics. The advantage of stratified sampling technique is the researcher will be able to determine how good the "stratum in the population is represented in the sample" (Ary, Jacob \& Razaveih, 1986, p.133). Stratification sampling provides an equal chance to people in the population to be chosen as sample Mohd Majid Konting (2004). This technique is appropriate for the group that is not homogenous and represents the subgroup differently.

The stratified sampling technique is appropriate for a research that requires small sample size. The population of the study were trainee counsellors from four (4) public universities which included UM, (UUM), (UMT) and (UMS). UM had 31 trainee counsellors, followed by UUM with 53 trainee counsellors. Meanwhile, UMT had 92 trainee counsellors and UMS 100 trainee counsellors. The stratified random sampling technique was administered. As a result, the number of sample on simple 
INTERNATIONAL JOURNAL OF ACADEMIC RESEARCH IN BUSINESS AND SOCIAL SCIENCES

Vol. 8, No. 12, Dec, 2018, E-ISSN: 2222-6990 @ 2018 HRMARS

calculation for each university were as follows: (1) UM - 13 trainee counsellors; (2) UUM - 23 trainee counsellor; (3) UMT - 40 trainee counsellors; and (4) UMS - 44 trainee counsellors (Table 1).

This research used the proportionate stratified random sampling corresponding to the different strata with similar sampling fractions. The number for the sample was decided based on the number of trainee counsellors in the population from each university using the stratified random sampling.

Table 1: Distribution of Questionnaires for Trainee Counsellors

\begin{tabular}{|l|l|l|l|l|l|}
\hline Institutions & Sample size & $\begin{array}{l}\text { Minimum } \\
\text { requirement }\end{array}$ & Return & Dismiss & Sample \\
\hline UM & 15 & 13 & 14 & 1 & 13 \\
\hline UUM & 25 & 23 & 24 & 1 & 23 \\
\hline UMT & 42 & 40 & 40 & 0 & 40 \\
\hline UMS & 50 & 44 & 47 & 3 & 44 \\
\hline Total & 132 & 120 & 125 & 5 & 120 \\
\hline
\end{tabular}

\section{Instrumentation}

Instruments for the supervision contextual factors Supervisors' and supervisees' counselling orientations were measured by the Selective Theory Sorter (STS). This instrument has 60 items and the Likert scale of the STS ranged from -3 not at all through +3 . The ranging scores from -3 indicated "not at all like you" through to +3 indicating "a lot like you". The items represented 12 types of theories. The supervisors' and supervisees' counselling orientations were matched and they were scored for each of the matching theory. These twelve (12) theories are categorised into four approaches. First, the integration of the psychodynamic approach which includes psychoanalytic therapy, Adlerian therapy, transactional analysis, Jungian, and integrative. Second, the humanistic approach which encompasses person centred therapy (PCT) Gestalt, and Existential theories. The behavioural approach includes the rational emotive behavioural therapy (REBT), behaviourism, and reality therapy; and lastly, the Cognitive Behavioural approach which consisted of cognitive behavioural therapy. The score for a 100 percent match is four, four for 75 percent match and two for 50 percent match and that means one for 25 percent match. An example of the STS item is "Goals of therapy should include assisting the clients in learning the consciousness of their responsibility, to bring unconscious spiritual factors to the conscious, and to recover meaning to existence".

Investigations on the supervisees' cultural knowledge and awareness during supervision was carried out using the Multicultural Counselling Knowledge and Awareness Scale (MCKAS) developed by Ponterotto, Gretchen, Utsey, Reiger, \& Autsin (2000) \& Szymanski (2003). The MCKAS has 32 items and it was used to measure the cultural knowledge and awareness during the supervision process. The scores from the knowledge and awareness sub-scales were used to measure the relationship and influence on the supervision outcomes. This instrument uses a seven - point (7) Likert scale, ranging from one (1) = "not at all true" through to four (4) = "somewhat true" and through to seven (7) = "totally true". An example of the MSKAS item is "I think that clients who do not discuss intimate 
aspects of their lives are being resistant and defensive". High scores on this scale represents good understanding of multicultural knowledge and awareness of the trainee counsellors.

Instruments for supervision outcomes to measure the supervisees' satisfaction, the Supervision Outcomes Survey (SOS) was utilised It is a 20 item survey questionnaire with the values of a sevenpoint (7) Likert scale ranging from 1 = "not at all" through $7=$ "greatest degree possible". The SOS was also used to measure the supervisees' view on the supervision including their level of satisfaction in the supervision (Worthen \& Isakson, 2000). An example the SOS item is, "Overall, I feel satisfied with my supervision". The total scores of the SOS were used to indicate trainee counsellors' general satisfaction towards supervision. Hence, high scores indicate the high satisfaction on the supervision process. In measuring the supervisees' performance during the internship, the Counsellor Performance Inventory (CPI) was used. The CPI was developed by lannelli (2000) with 41 items. The $\mathrm{CPI}$ uses a five - point (5) Likert scale ranging from one (1) = "disagree strongly" through five (5) = "agree strongly". High scores reflect high supervisees' performance. An example of the CPI item is "the counsellor accurately reflects the clients".

\section{Research Procedures}

In conducting the data collection, the approval from the Deans and Heads of Department were required. In this research, the equal percentage of respondents from each of the selected universities was required in order to receive the high return rate from the respondents. The personal approach enabled the researcher to receive direct feedbacks from the respondents.

Questionnaires were either mailed directly to the respondents or self distributed by the researcher. Questionnaires for UM and UMS were distributed by mail but self distributed to UUM and UMT by the researcher. Questionnaires for the supervisors were also similarly distributed. The respondents who completed the questionnaires by mail, returned them directly to the researcher. The follow up process was done via email or telephone in obtaining the data. After receiving the responses from the respondents, the pairing process was carried out by the researcher. The questionnaires which paired the trainee counsellors and supervisors were deemed valid questionnaires. Among the 125 trainee counsellors and 20 supervisors who returned the questionnaires, only 120 from the trainee counsellors and 18 from the supervisors were considered valid.

In ensuring the data from the respondents (trainee counsellors and supervisors) were matched, codes were used in order to label each questionnaires. The codes were necessary for they assist the researcher to identify the respondents' university when they returned the questionnaires. For the UM trainee counsellor, the codes were numbered from V101, V102 and so forth. For the UM supervisor, the codes were S101, S102 and so forth. The completed data were used to conduct the descriptive and inferential analyses. The descriptive analyses consisted of the mean, standard deviation and frequency. Inferential analyses comprised of the Pearson product moment correlation and stepwise regression. 


\section{Data Analysis}

The descriptive analyses were used to analyse the demographic factors. The inferential analyses were used to analyze the supervisory relationship (supervisees' working alliance, supervisees' role conflict, supervision interaction and supervisors' attributes) and supervision contextual factors (supervisors' and supervisees' counselling orientation and supervisees' cultural knowledge and awareness) and how these variables might relate and influence the supervision outcomes (supervisees' satisfaction and performance).

Correlation coefficient and multiple regression were appropriate for measuring various types of issues in behavioural research (Cohen \& Cohen, 1983, Pedhazur, 1982; Mc Neil, Kelly \& Mc Neil, 1975 and Ward \& Jennings, 1973). Therefore, the Pearson product moment correlation coefficient and Multiple Regression analysis tests were chosen to analyse the data. Cohen (1988) stated to ensure the accuracy of a correlation test, the effect size index has to be considered. The difference in the result is not a simple function. However, discussion on correlation is based on Pallant's (2010) correlation analysis to describe the strength and direction of the linear relationship between two variables. There are several statistics available from the SPSS, depending on the level of measurement and nature of data. Pearson $(r)$ is designed for interval level (continuous) variables. Pearson product moment correlation coefficient values range from -1 to +1 . The negative $(-)$ and positive $(+)$ signs indicate whether there is positive correlation (as one variable increases, so too the other) or a negative correlation (as one variable increases, the other decreases). The signs determine the strength of the relationship. Value 1 or -1 indicates perfect correlation, which is described by the straight line of the scatterplot; and 0 value indicates no relationship between the two variables (Pallant, 2010).

\section{Results}

\section{Demographic Data}

The sample consisted of 19.2 percent males $(N=23)$ and 80.8 percent females $(N=97)$. Majority of the respondents were females. Ethnically, there were 75.8 percent Malays $(N=91), 8.3$ percent Chinese $(\mathrm{N}=10)$, followed by 2.5 percent $(\mathrm{N}=3)$ Indians and 13.3 percent were from other ethnic groups (i.e: Dusun, Bajau, Iban, Bidayuh, Melanau). Malay respondents formed the majority.

All respondents were final year undergraduate students of the Bachelor Degree of Guidance and Counselling and undergoing their internship programme. Their internship placement were 5.8 percent $(\mathrm{N}=7)$ in the school setting $(\mathrm{N}=7), 40.8$ percent at the university/college/counselling centre, and 53.3 percent were at other organisations (i.e Malaysian prison, Department of Welfare, Police Department, Hospital and Parol Centre)

Fifty seven point one (57.1) percent $(N=68)$ of the trainee counsellors selection was made by the department/ faculty. Twenty one $(21)$ percent $(N=4)$ were the supervisor's choice and 3.4 percent $(\mathrm{N}=25)$ were the trainee counsellors' choice. Meanwhile, 5.9 percent was made based on an agreement between the trainee counsellors and the department / faculty, and 12.6 percent was based on the mutual decision between the supervisor and trainee counsellor. Less than $1 \%(0.8)$ of the respondents did not answer this question. 
Fifty-three point three (53.3) reported expertness as the main factor whereas 7.5 percent trustworthiness as the main factor. Only 3.3 percent described attractiveness as the influencing factor in selecting the supervisor. Twentyfive point eight (25.8) percent did not respond to this question. James and Baldwin (1999) described a good supervisor as a person who encourages autonomy and independence, promotes flexibility, displays friendliness, and expertness in the research field, ensures regular contact.

Eighty-three point three (83.3) reported they had personally selected theirs supervisor whereas 15.8 percent reported their current supervisors were not their choice. As for the supervisors' ethnic background, Malays made up 66.7 percent of the sample $(N=12)$. Sixteen point six (16.6) percent ( $N$ $=3$ ) were Chinese and 16.6 percent $(\mathrm{N}=3)$ were from other ethnic groups (i.e; Dusun, Murut, Iban, and Bidayuh). The highest degree level attained by the supervisors were the M.A/M.Ed/M.Sc (55.6\%) and 44.4 percent PhD/Ed.D

Ho1: There is no significant relationship between supervisors' and supervisees' counselling orientation and supervision outcomes

Pearson product moment correlation coefficient was used to analyse the hypothesis. The results revealed there was no significant correlation between the supervisors' and supervisees' counselling orientation and supervision outcomes, $r=.11$ at $p>.05$. In conclusion there was no relationship between the supervisors' and supervisees' counselling orientation and supervision outcomes. Thus, the null hypothesis was accepted

Ho2: There is no significant relationship between supervisees' cultural knowledge and awareness and supervision outcomes

To analyze this hypothesis, the Pearson product moment correlation coefficient was used to measure the relationship between the supervisees' cultural knowledge and awareness and supervision outcomes. The output showed there was no significant correlation between the supervisees' cultural knowledge and awareness and supervision outcomes, $r=.17$ at $p>.05$. In conclusion the supervisees' cultural knowledge and awareness had no relationship with supervision outcomes. Therefore, the null hypothesis was accepted 
INTERNATIONAL JOURNAL OF ACADEMIC RESEARCH IN BUSINESS AND SOCIAL SCIENCES

Vol. 8, No. 12, Dec, 2018, E-ISSN: 2222-6990 @ 2018 HRMARS

Table 2: Pearson Product Moment Correlation Coefficient of Supervisors' and Supervisees' Counselling Orientation and Supervisees' Cultural Knowledge and Awareness and Supervision Outcomes

\begin{tabular}{|l|l|l|}
\hline Scales & 1 & 2 \\
\hline Supervision contextual factor & & \\
\hline 1. SSCO & - & \\
\hline 2. SCKA & .05 & \\
\hline SO & .11 & .17 \\
\hline
\end{tabular}

SSCO = Supervisor and supervisees counselling orientation; SCKA = Supervisees' Cultural Knowledge and Awareness; $\mathrm{SO}=$ Supervision Outcomes

\section{Discussion}

For research hypothesis 1, there was no significant correlation between the supervisors' and supervisees' counselling orientation and the supervision outcomes. In the previous research, there was no relationship between the theoretical orientation of supervisors and the therapy outcomes (Poznanski \& McLennan, 2003). There were recommendations to investigate the impact of theoretical orientation on the supervision outcomes (Lochner \& Melchert, 1997) however, these recommendations did not materialise. Gelso (1995) also highlighted the difficulty in measuring theoretical orientations empirically. This hypothesis was also consistent with hypothesis 11 of the study. There was not much development in the study of relationship between the theoretical orientation and supervision outcomes. The pattern was consistent whereby the theoretical orientation was not an important factor in evaluating the supervision outcome. Other than that, the understanding and application of theoretical orientation might be new for trainee counsellors in managing the counselling process. This researcher concludes, the trainee counsellors were not familiar with theoretical orientation and this may be the cause for the insignificant correlation between the supervision of contextual factors (supervisors' and supervisees' counselling orientation and supervisees' cultural knowledge and awareness) and supervision outcomes.

For hypothesis 2 there was no correlation between the supervisees' cultural knowledge and awareness and supervision outcomes. This contradicted with Inman's (2006) study. Inman reported the supervisees with cultural sensitivity would be more likely to have an increased level of satisfaction in supervision. Green and Dekker (2010) also indicated there was a correlation between cultural sensitivity and satisfaction towards supervision. Multicultural knowledge and awareness is a newly developed area in the counselling practice in Malaysia and in time it may contribute to the findings of the current study. This hypothesis was also aligned with hypothesis 11 of the study.

\section{Recommendations}

For future research, the independent variables for the supervision of contextual factors (cultural knowledge and awareness) should be examined from the supervisors' perspectives. Therefore, the information from the supervisors' perspectives can be cross checked with information from the trainee counsellors. From this information, the researcher can make a concrete conclusion on cultural 
influence on supervision outcomes. Future researchers should personally explain to the respondents when they want to answer the questions on supervision of contextual factors (supervisors' and supervisees' counselling orientation). A clear understanding of the of this variable is important before they answer the questions.

Future researchers are encouraged to use the interview technique in obtaining additional information in the study. The questionnaire should be designed to include subjective questions (open ended questions) to generate subjective opinions from the respondents (trainee counsellors and supervisors). Future researchers can also consider expanding the variables for supervision of contextual factors such as the level and setting of experience. Expanding the factors may increase the factors or variables that may influence the supervision outcomes. The information acquired from these factors or variables will also contribute to the choice of setting the supervisees or trainee counsellors when undergoing internship or practicum as well as the choice of supervisors. Supervisees or trainee counsellors will be able to choose supervisors whom they think are capable to manage their supervision process during internship or practicum.

\section{Conclusion}

The supervision of contextual factors (supervisors' and supervisees' counselling orientation and supervisees' cultural knowledge and awareness) were not correlated nor influenced supervision outcomes. To support these findings the researcher provided the previous research results that showed no significant correlations of the contextual factors with supervision outcomes and also findings that showed these factors did not influence supervision outcomes. The researcher also presented several limitations in this research. These include the limitation in data gathering due to the lack of co-operation from supervisors and limited number of universities involved in the research. Hence the findings could not be generalised as well as the supervision process was changed based on situations. At the same time, the limited scope of the research itself which only investigated on the relationship with and the influences of variables on the supervision outcomes. From this present research, the researcher recommended future researchers to expand the research variable cultural knowledge and awareness from supervisor's perspectives. Apart from that, the personal explanation by researcher are encourage when answering questions for supervision contextual factors and investigation on the difference of supervision interaction between supervisor and trainee counsellor. Respondents are easy to understand the questions through direct explanation from researcher. Deeply understand the. As a conclusion, recommendations from this present research are able to assist future researchers to expand their research.

\section{References}

Ary, D., Jacobs, L. C. \& Razavieh, A. (1986). Introduction to research education. Library of Congress Cataloging in Publication Data: USA.

Borders, L., D. \& Brown, L. L. (2005). The New Handbook of Counseling Supervision. Lawrence Erlbaum Associates Publishers: New Jersey. 
INTERNATIONAL JOURNAL OF ACADEMIC RESEARCH IN BUSINESS AND SOCIAL SCIENCES

Vol. 8, No. 12, Dec, 2018, E-ISSN: 2222-6990 @ 2018 HRMARS

Breaux, W. W. (2005). The relationship between the cultural competence of counsellor supervisors and the satisfaction with supervision of their supervisees. PhD Dissertation. New Orleans University.

Brown, M. T., \& Landrum-Brown, J. (1995). Counselor supervision: Cross-cultural perspectives. In J. G. Ponterotto, J. M. Casas, L. A. Suzuki, \& C. M. Alexander (Eds.), Handbook of multicultural counseling (pp. 263-286). Thousand Oaks, CA: Sage.

Caplan, R.D., and Jones, K.W. (1975). Effects of Work Load, Role Ambiguity, and Type A Personality on Anxiety, Depression, and Heart Rate. Journal of Applied Psychology, 713-719.

Chang, C. Y., Hays, D. G., \& Shoffner, M, F, (2003). Cross-racial supervision: A developmental approach for White supervisors working with supervisees of colour. The Clinical Supervisor, 22, 121 138. doi:10.1300/J001v22n02_08

Cohen, J. (1988). Statistical power analysis for the behavioral sciences. Second Edition. Hillsdale, NJ: Lawrence Erlbaum Associates, Publishers.

Cohen, J., (1983). Applied multiple regression/ correlation analysis for the behavioral sciences. Hillsdale NJ:Erlbaum.

Duan, C., \& Roehlke, H. (2001). Assessing the barriers and changes of cross cultural supervision: A case study: Counsellor Education \& Supervision, 38, 191-204.

Gatmon (2001). Issues and challenges of different multicultural supervision triads. Power Point Presentation from Chia-Chih DC Wang. University of Missouri Kansas City. USA.

Gelso, C. J. \& Carter, J., A. (1985). The relationship in counselling and psychotherapy: Components consequences, and theoretical antecedents. The Counselling Psychologist, 13, 155-243.

Green, M. S., \& Dekkers, T. D. (2010). Attending to power and diversity in supervision: An exploration of supervisee learning outcomes and satisfaction with supervision. Journal of Feminist Family Therapy, vol. 22, 293-312.

Green, M., S., \& Dekkers, T., D. (2010). Attending to power and diversity in supervision: An exploration of supervisee learning outcomes and satisfaction with supervision. Journal of Feminist Family Therapy, vol. 22, 293-312.

Iannelli, R. J. (2000). A structural equation modeling examination of the relationship between counseling self-efficacy, counseling outcome expectations, and counselor performance. Unpublished doctoral dissertation, University of Missouri-Kansas City.

Inman, A.G. (2006).Supervisor multicultural competent and its relation to supervisory process and outcome. Journal of Marital and Family Therapy, 32, 73-85.

Jackson, J., L., Jr. (2010). Theoretical counseling orientation: An initial aspect of professional orientation and identity. PhD Dissertation. University of Alabama.

Ladany, N., \& Bradley, J., B. (2010). Counselor Supervision. Taylor \& Francis: New York.

Ladany, N., Ellis, M. V., Friedlander, M. L., \& Stern, M. (1992). The supervisory working alliance: Its relation to trainee self-efficacy and satisfaction with supervision. Poster session presented at the meeting of the American Psychological Association, Washington, DC.

Lochner, B. T., \& Melchert, T. P. (1997). Relationship of cognitive style and theoretical orientation to psychology interns" preferences for supervision. Journal of Counseling Psychology, 44(2), 256260. 
INTERNATIONAL JOURNAL OF ACADEMIC RESEARCH IN BUSINESS AND SOCIAL SCIENCES

Vol. 8, No. 12, Dec, 2018, E-ISSN: 2222-6990 C 2018 HRMARS

Konting, M. M. (2004). Kaedah Penyelidikan Pendidikan. Dewan Bahasa dan Pustaka. Dawana Sdn.Bhd.: Kuala Lumpur.

Pallant, J. (2010). SPSS survival manual: A step by step guide to data analysis using SPSS. Mc Graw Hill: New York.

Pedhazur, E. J. (1982). Multiple regression in behavioral research: explanation and prediction. Holt, Riehart and Winston, Inc: New York.

Ponterotto, J., G., Gretchen, D., Utsey, S., O., Reiger, B., P., \& Autsin, R. (2000). A revision of the multicultural counselling awareness scale. Journal of Multicultural Counselling and Development, 30, 153-181.

Poznanski, J., J., \& McLennan, J. (2003). Becoming a Psychologist with a Particular Theoretical Orientation to Counselling Practice. Australian Psychological Society. doi: 10.1080/000500603100 1707247

Putney, W., P., Everett, L., W., \& Michael, E., M. (1992). Effects of supervisor and supervisee theoretical orientation and supervisor-supervisee matching on interns' perceptions of supervision. Journal of Counseling Psychology, 39 (2), 258-265, doi. 10.1037/00220167.39.2.258

Putney, W., Jr and McCullough (1992). Effects of supervisor and supervisee theoretical orientation and supervisor-supervisee matching on interns" perceptions of supervision. Journal of Counselling Psychology, vol. 39 (2), 258265.

Storm, C. L. (2002). Teaching therapists to become supervisors. In T. C. Todd \& C. L. Storm (Eds.), The complete systemic supervisor: Context, philosophy, and pragmatics (pp. 363-372). Lincoln, NE:Authors Choice Press.

System Approach of Supervision Model (1995). Training Counselling Supervisors. SAGE Publications: London.

Szymanski, D. M. (2003). The feminist supervision scale: A rationale/theoretical approach. Psychology of Women Quarterly, 27, 221-232.

Jaafar, W.M.W. (2007). Pengaruh Perkembangan Penyeliaan Dan Efikasi Swadiri Kaunseling Terhadap Prestasi Kaunselor Pelatih. PhD thesis, Universiti Putra Malaysia.

Wan Marzuki Wan Jaafar (2011). The counselling performance among trainee counsellor in Malaysia. SciVerse Science Direct., 30, 512-516.

Ward, Joe H Jr., \& Jennings, E. (1973) Introduction to Linear Models. Prentice-Hall: Englewood Cliffs, NJ.

Wood, C. (2005). Supervisory working alliance: A model providing direction for college counseling supervision. Journal of Counseling, 8, 127-137.

Worthen, V., E., \& Isakson, R., L. (2000). The Supervision Outcomes Survey (SOS). In Falender \& Shafranske (2004).

Worthington, E. L. (1987). Changes in supervision as counselors and supervisors gain experience: A review. Professional Psychology, 18, 189-208. 